\title{
THE Ti/c-Si SOLID STATE REACTION
}

\section{An ellipsometrical study}

\author{
J.M.M. DE NIJS * and A. VAN SILFHOUT \\ Department of Solid State Physics, University of Twente, P.O. Box 217, 7500 AE Enschede, The Netherlands
}

Received 28 February 1989; accepted for publication 17 July 1989

\begin{abstract}
This paper is the first of a series of three articles in which we present the results and analyses of an extended study of the c-Si/Ti solid state reaction. In this paper we will discuss the spectroscopic ellipsometric investigation. Thin $(\sim 10 \mathrm{~nm}) \mathrm{Ti}$ films are grown on clean $\mathrm{Si}(111)$ surfaces and are subsequently heated. The $\mathrm{Si}$ indiffusion and the $\mathrm{Si}-\mathrm{Ti}$ intermixing are continuously registered by three-wavelengths ellipsometry. Two metastable intermediate phases are observed to form before the final state is obtained. Spectroscopic ellipsometry $(E=2-4.5 \mathrm{eV})$ is used to characterize the as-deposited layer, the metastable intermediate phases and the final state. Analysis of these spectra shows that: (1) $\mathrm{Si}$ and $\mathrm{Ti}$ intermix during the initial Ti deposition, (2) a fast reordering of the Ti atoms occurs when the system is slightly heated $\left(\sim 175^{\circ} \mathrm{C}\right)$, (3) a metastable, probably monosilicide phase with a large Si concentration gradient is obtained at $\sim 350^{\circ} \mathrm{C}$, (4) a homogeneous metastable $\mathrm{TiSi}_{2}$ forms at $\sim 450^{\circ} \mathrm{C}$, and, at $\sim 700^{\circ} \mathrm{C}$ a roughened $\mathrm{TiSi}_{2}$ layer with a surplus of $\mathrm{c}-\mathrm{Si}$ is formed.
\end{abstract}

\section{Introduction}

Silicides and in particular refractory-metal silicides have attracted a lot of attention during the last decade as a result of the very fast developments in modern semiconductor industry [1]. This enhanced interest originates from the need of a low-resistance substitute for doped poly-crystalline silicon [1,2], good electrical contacts and Schottky barrier rectifiers [3]. A number of silicides, such as $\mathrm{Ni}_{2} \mathrm{Si}$ and $\mathrm{CO}_{2} \mathrm{Si}$ can be epitaxially grown on crystalline $\mathrm{Si}$ (c-Si), which offers new prospects for the metal base transistor $[4,5]$.

Titanium-disilicide has presented itself as the most promising substitute for doped poly-silicon; its application in semiconductor technology can be expected any moment from now. The solid state reaction of pure metal $\mathrm{Ti}$ and $\mathrm{Si}$ has shown to yield Schottky barriers of good reliability and reproducibility [5], whereas the $\mathrm{Ti}-\mathrm{Si}$ solid state

* Present address: Department of Physics, Eindhoven University of Technology, P.O. Box 513, 5600 MB Eindhoven, The Netherlands. reaction has found a particular application in self-aligned technology [1,6]. Although $\mathrm{TiSi}_{2}$ is not far from being applied in semiconductor industry, the solid state reaction is but poorly understood.

Previous investigation [7-9] all show that at high temperatures $\left(\sim 700^{\circ} \mathrm{C}\right)$ the pure $\mathrm{Ti}$ and $\mathrm{Si}$ from the substrate intermix, yielding a low-ohmic $\mathrm{C} 54 \mathrm{TiSi}_{2}$ alloy. A general consensus on the kinetics of this intermixing process, however, could not be established; most of the investigations published yet report highly contradicting results. Already the room-temperature ( $\mathrm{RT}$ ) $\mathrm{Ti}$ deposition has evoked a lot of discussion. Butz et al. [7] and Taubenblatt and Helms [10] claim that the $\mathrm{Ti}-\mathrm{Si}$ interface remains unreacted, whereas the work of a number of others [11-14] shows that the initially deposited $\mathrm{Ti}$ atoms react with the $\mathrm{Si}$ from the substrate forming a thin $(-3 \mathrm{~nm})$ intermixed region prior to the growth of a purely $\mathrm{Ti}$ layer. According to Vähäkangas et al. [15], this discrepancy should be attributed to the method of surface cleaning, nevertheless, the majority of the studies yet performed are in favor of mixing. Such 
an intermixing is also expected from a consideration of the reaction enthalpy; the $\mathrm{Ti}-\mathrm{Si}$ intermixing is highly exothermic ( $31 \mathrm{kcal} / \mathrm{mol})$ [1]. In this paper it will be reported that our result presently obtained confirms the concept of the intermixed $\mathrm{Ti}-\mathrm{Si}$ interface.

Raising the temperature above $-250^{\circ} \mathrm{C}$ enforces $\mathrm{Si}$ diffusion into the $\mathrm{Ti}$ overlayer [16-19]. This process is studied by several authors, however, their results do not allow the extraction of a unique reaction kinetics because of the lack of agreement. Chambers et al. [16] have heated a 10 $\mathrm{nm}$ Ti layer during $1.5 \mathrm{~h}$ at $340^{\circ} \mathrm{C}$. They observed that the $\mathrm{Ti}$ layer was converted to effectively a TiSi layer. Butz et al. [7] report that a similar Ti layer annealed at $300^{\circ} \mathrm{C}$ during $1 \mathrm{~h}$ has a composition near that of $\mathrm{TiSi}_{2}$. Further, according to the work of Tromp et al. [17,18], a $\mathrm{TiSi}_{0.85}$ overlayer is obtained if a $2.5 \mathrm{~nm}$ Ti layer is heated during 10 $\min$ at $4^{\circ} \mathrm{C}$. From an extensive study by Raaijmakers [8] it shows that annealing the $\mathrm{Ti}-\mathrm{Si}$ system upto $500^{\circ} \mathrm{C}$, yields a layer of very fine, possibly orthorhombic crystalline material of equiatomic composition. Hence, the studies yet performed are not only scarce, but apparently highly contradicting too.

Structural analyses of co-sputtered $\mathrm{TiSi}_{2}$ layers have revealed that Ti-disilicide occurs in two crystal structures: at low temperatures $\left(<350^{\circ} \mathrm{C}\right)$ a $\mathrm{C} 49$ structure nucleates which, at $-700^{\circ} \mathrm{C}$ converts to the desired low-ohmic disilicide $[8,9,20,21]$. The latter has a C54 structure. Both structures are successively observed by Raaijmakers for the $\mathrm{Ti} / \mathrm{c}-\mathrm{Si}$ and $\mathrm{Ti} / \mathrm{a}-\mathrm{Si}$ solid state reaction. However, a peculiar difference was found for the growth at $T=500^{\circ} \mathrm{C}$; at that temperature a metastable $\mathrm{C} 49$ was obtained for the $\mathrm{Ti} / \mathrm{a}-\mathrm{Si}$ reaction whereas the $\mathrm{Ti} / \mathrm{c}-\mathrm{Si}$ had yielded a possibly crystalline material of approximately TiSi composition [8].

In the present study we have grown $\mathrm{Ti}$ layers $\sim 10 \mathrm{~nm}$ thick on clean, reconstructed $\mathrm{Si}(111)$ substrates inside an UHV system. These layers are subsequently heated. The process of $\mathrm{Si}$ indiffusion is continuously followed by three-wavelengths ellipsometry. Increasing the temperature very slowly made it possible to distinguish several metastable intermediate phases that occur prior to a final transition at $\sim 700^{\circ} \mathrm{C}$. We have characterized these intermediate phases by means of spectroscopic ellipsometry ( $E=2-4.5 \mathrm{eV}$ ) and a number of additional techniques.

Analyses of the optical spectra showed the following. The as-deposited $\mathrm{Ti}$ layer has initially reacted with the silicon substrate and a thin (2-4 $\mathrm{nm})$ mixed region has formed before being overgrown by a pure $\mathrm{Ti}$ layer.

The first process of $\mathrm{Si}$ indiffusion commenced already at temperatures below $200^{\circ} \mathrm{C}$ and it terminated at $\sim 350^{\circ} \mathrm{C}$, probably because all pure Ti had been consumed. Analysis shows that this state is inhomogeneous, a large concentration gradient for $\mathrm{Si}$ expected, and of roughly equiatomic composition.

Raising the temperature initiates a second $\mathrm{Si}$ indiffusion at $-400^{\circ} \mathrm{C}$, ultimately yielding a stoichiometric $\mathrm{TiSi}_{2}$ at $\sim 450^{\circ} \mathrm{C}$. This phase corresponds with the metastable, polycrystalline $\mathrm{C} 49$ disilicide observed by Raaijmakers [8]. The surface is silicon enriched and has a composition close to that of $\mathrm{TiSi}_{3}$. This $\mathrm{C} 49$ disilicide is stable upto $\sim 700^{\circ} \mathrm{C}$, when a final transition yields a layer of probably large C54 disilicide islands embedded in a crystalline Si matrix.

The results of our study will be published in three separate papers. In this article we report on the results of the optical study of the $\mathrm{Ti} / \mathrm{c}-\mathrm{Si}$ solid state reaction. Other samples, identical to the intermediate states were prepared and subjected to in-situ AES and ex-situ XPS, RBS measurements and AES $\mathrm{Ar}^{+}$depth profiling. This work is presented in the second paper. The optical real time registrations of the various $\mathrm{Si}$ diffusion processes are particularly suited for the study of the diffusion fronts. In a third article we will discuss the growth of the monosilicide phase.

This paper is organized as follows. First, we shall shortly discuss the dielectric function of $\mathrm{c}-\mathrm{Si}$ and the information depth for ellipsometry. The experimental conditions are subsequently depicted. In section 4 we present the results of the measurements. The analyses of the observed intermediate states are treated in section 5 , and the paper closes with a discussion of the optical results. 


\section{The dielectric function of $\mathrm{c}-\mathrm{Si}$ and the information depth}

In fig. 1 we have depicted the dielectric function $\tilde{\varepsilon}(E)$ of $\mathrm{c}-\mathrm{Si}$ at room temperature (RT) and at $-250^{\circ} \mathrm{C}$, as it is measured on a clean $\mathrm{Si}(111)$ sample inside our UHV system. The RT result is in good agreement with the functions reported in the literature $[22,23]$. The shift of $\tilde{\varepsilon}(E)$ caused by the heating is reversible and can be ascribed to narrowing of the bandgap due to the lattice expansion and an enhanced electron-lattice interaction [24]. Similar shifts were previously observed upon heating $\mathrm{Ge}$ [25], $\mathrm{Si}$ at $30 \mathrm{~K} \mathrm{[26]} \mathrm{and} \mathrm{Ag}$ [27].

It shall be obvious that this temperature dependency affects the measurements, ultimately leading to erroneous interpretations. It is for this reason that all spectroscopic ellipsometric measurements have to be performed at RT.

The information depth for the samples presently studied is limited by (1) the penetration depth of the electromagnetic field and by (2) the reflection coefficient of the silicide/silicon interface. The penetration depth $d_{\lambda}$ given by:

$d_{\lambda}=\lambda / 4 \pi k, \quad k=\operatorname{Im}(\tilde{n})$,

with $k$ the extinction coefficient. In fig. 2 we have

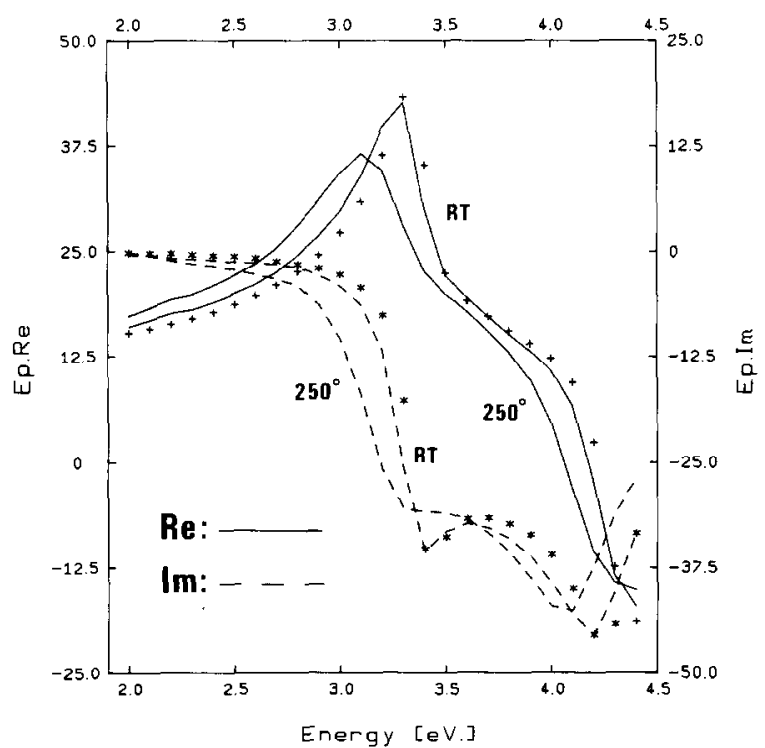

Fig. 1. Dielectric function of c-Si from the literature $(*$ and + ) and as measured at RT and at $T \approx 250^{\circ} \mathrm{C}$.

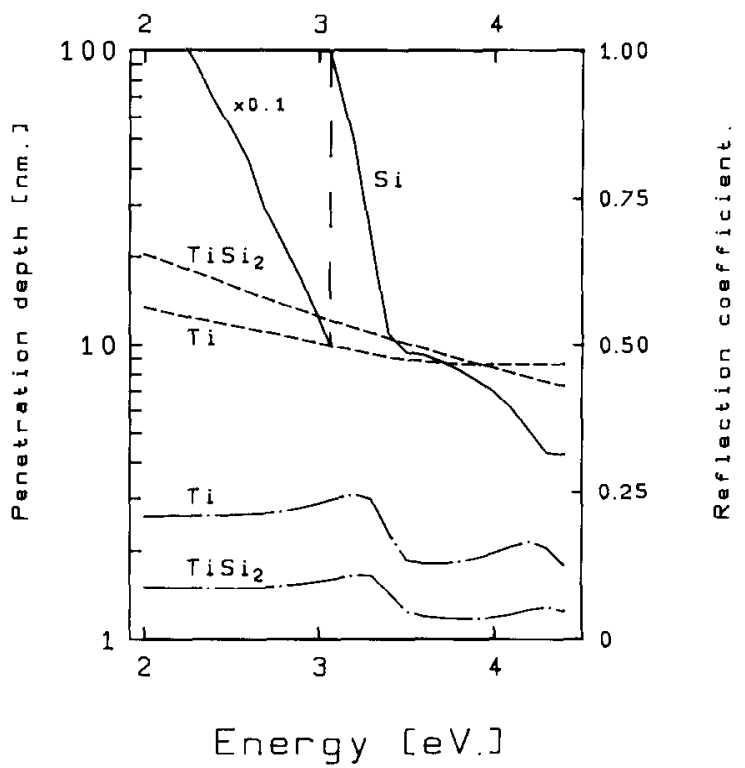

Fig. 2. Penetration depth of $\mathrm{c}-\mathrm{Si}$ (solid line), $\mathrm{Ti}$ and $\mathrm{TiSi}_{2}$ (dashed lines). The dashed-dotted lines denote the reflection coefficients of the $\mathrm{Ti}-\mathrm{Si}$ and the $\mathrm{TiSi}_{2}-\mathrm{Si}$ interfaces.

depicted the penetration depths of $\mathrm{c}-\mathrm{Si}, \mathrm{Ti}$ and C49 $\mathrm{TiSi}_{2}$. The dielectric function of $\mathrm{Ti}$, which is used for the calculation of $d_{\lambda}$ is previously measured [28], whereas $\tilde{\varepsilon}(E)$ for $\mathrm{TiSi}_{2}$ is a preliminary result of section 5 .

A second restriction on the information depth is imposed by the reflectivity of the silicide-silicon interface. Suppose that the interface is perfectly transparent, in that case there should be no EM field reflected from the interface and the detected light beam does not contain any information on the interface; a decreasing reflectivity implies a diminishing interface sensitivity and an increasing surface sensitivity.

In the case of materials with a large dielectric constant, the transmitted beam propagates nearly normal to the surface. An estimation for the reflectivity then can be obtained from a consideration of the perpendicular reflectivity at the silicide-silicon interface, or,

$\tilde{r}_{i j}=\left(\tilde{n}_{i}-\tilde{n}_{j}\right) /\left(\tilde{n}_{i}+\tilde{n}_{j}\right)$,

where $\tilde{n}_{i}$ and $\tilde{n}_{j}$ denote the complex refractive indices of the silicide and silicon. In fig. 2 we have depicted for the $\mathrm{TiSi}_{2}-\mathrm{Si}$ and the Ti-Si interface, 
showing that the reflectivity of the $\mathrm{TiSi}_{2}-\mathrm{Si}$ interface has decreased as compared to that of the Ti-Si interface. Furthermore, the increased light absorption of the c-Si for $E>3.4 \mathrm{eV}$ clearly diminishes the reflectivity, i.e., the short wavelengths shall be less depth sensitive as compared to the long wavelengths.

Based upon the arguments mentioned above, we have chosen the wavelengths for the timedependent measurements. The shortest wavelength, $340 \mathrm{~nm}$ or $3.65 \mathrm{eV}$, lies well within the absorbing region, and is more surface sensitive. The other two wavelengths (450 and $550 \mathrm{~nm}$ ) are located in the non-absorbing region and are depth sensitive.

\section{Experimental}

For the in-situ experiments, an UHV system comprising a main chamber, a loading system and a preparation chamber is used. The base pressure in the main system is $2 \times 10^{-10}$ Torr and that in the preparation system $5 \times 10^{-10}$ Torr. The experimental facilities include an $\mathrm{Ti}$ evaporation source, the $\mathrm{Ti}$ being evaporated from a directly heated $\mathrm{Ti}$ wire, an Auger system (retarding field analyzer), an $\mathrm{Ar}^{+}$ion gun and a spectroscopic rotating-analyzer ellipsometer (RAE) similar to that described in refs. $[29,30]$, in the energy range of $2-4.5 \mathrm{eV}$.

For the present investigation, polished Si(111), $\Omega=500 \Omega / \mathrm{cm}$ samples are used. Prior to placing these samples in the UHV system, the samples are rinsed ultrasonically and boiled in 2-propanol. Inside the UHV system, the samples are $\mathrm{Ar}^{+}$ sputtered, $E_{\mathrm{Ar}}=2 \mathrm{keV}, I_{\mathrm{Ar}}=3 \mu \mathrm{A} / \mathrm{cm}^{2}$ during 30 min. After $10 \mathrm{~min}$ of sputtering, the samples are heated gradually up to $800^{\circ} \mathrm{C}$ and annealed at that temperature for another $30 \mathrm{~min}$. The thus obtained surfaces showed only slight traces of $\mathrm{C}$ contamination, just above the detection limit for $\mathrm{C}$ by AES, and no traces of $\mathrm{O}$ or Ar.

The temperature is measured from a $\mathrm{Pt}$ resistance-thermometer mounted to the backside of the $\mathrm{Si}$ sample. It was found that the resistance-thermometers offered a reproducible but slow $(\tau \approx 1$ min) measure for the temperature. The Pt ther- mometer was calibrated at high temperature by a pyrometer and at RT. The intermediate temperatures are obtained from interpolations of the high and low temperature calibrations. Nonetheless, one should not disparage errors in the surface temperature thus obtained; errors up to $25-50^{\circ} \mathrm{C}$ might be possible. The samples are heated by a direct current; an accurate control of the heating current warranted well reproducible sample temperatures.

The deposition rate of the $\mathrm{Ti}$ source was difficult to control from one experiment to another and deposition rates varied between 0.4 and 0.75 $\mathrm{nm} / \mathrm{min}$. Upon termination of the deposition process, the sample is characterized by a spectroscopic ellipsometric scan.

The heating of the samples is performed by an interactive, computer controlled system. The RAE is completely automated and controlled by a LSIPDP11 micro-computer [30]. It is equipped with a Xe light source in combination with a monochromator. The angle of incidence was $68.5^{\circ}$ in all experiments. The interactive computer program permitted five options: (1) control of the annealing current, (2) the temperature can be measured at any moment, (3) a spectroscopic ellipsometric scan from 2-4.5 eV comprising 25 energies, (4) a fast (within $30 \mathrm{~s}$ ) determination of the ellipsometric parameters $\Delta$ and $\Psi$ at three wavelengths with a precision better than $0.02^{\circ}$ for both $\Delta$ and $\Psi$ and (5) the measurement of $\Delta$ and $\Psi$ at three wavelengths at a number of equidistant time intervals. The first spectroscopic ellipsometric scan and the first three-wavelengths measurement are twozone measurements [31,32]; $\Delta$ and $\Psi$ are determined twice, one time at a polarizer angle of $45^{\circ}$ and a second time at $-45^{\circ}$. Averaging both results, eliminates all systematic errors in first-order except those in $\Delta$ caused by the windows. An estimation of the errors in $\Delta$ due to these windows can now be obtained from the differences in $\Delta^{+45}$ and $\Delta^{-45}$; errors $\delta \Delta$ are found to be less than $1.5^{\circ}$ for $E=2 \mathrm{eV}$ while they increase with the energy up to $2.5^{\circ}$ for $E=4.4 \mathrm{eV}$. The calibration parameters [33] for the RAE are determined on a sample outside the UHV system; the optical benches supporting the ellipsometer can be rotated until they point outside the system while they rotate in the same geometrical plane. 
This procedure is preferred, because it eliminates calibration errors caused by the windows. Zone errors in $\Delta$ and $\Psi$ on a sample outside the UHV system were less than $0.50^{\circ}$ for $\Delta$ and less than $0.2^{\circ}$ for $\Psi$, which indicates that the calibration is quite accurate and that second-order errors are negligible for these samples. Hence, the main errors are caused by the birefringence of the windows [31]. The second and subsequent ellipsometric measurements are single-zone measurements which are corrected by the previously determined twozone differences.

The grown layers were slowly annealed, which often took several hours. This process is followed continuously at the three wavelengths, 340,450 and $550 \mathrm{~nm}$. The longest wavelength is more depth sensitive as compared to the shortest, whereas the shortest is more surface sensitive. In a number of cases, we have characterized the intermediate stages of the distinguishable diffusion processes by spectroscopic ellipsometry. For this purpose the sample has to be cooled down to RT, other- wise one gets problems in the interpretation of these scans (see section 2). Distorting side-effects on the growth kinetics due to these interruptions were not observed.

\section{Experimental results}

About 14 experiments have been performed. In fig. 3 we have displayed the generally observed changes of $\Delta$ and $\Psi$ as a function of temperature for a $\mathrm{Ti}$ layer of $\sim 10 \mathrm{~nm}$ which has been deposited in $15 \mathrm{~min}$. One should note that the layer thickness is such that any changes of the optical character of the layer and its thickness can be observed. The inset shows $\Delta_{340}$ as a function of time. Commencing at the low temperature side, we observe an initially strong increase of $\Delta$ for all wavelengths at $T \approx 150-200^{\circ} \mathrm{C}$. No changes are observed below that temperature, indicating that the layer withstands a small temperature increment, but once the temperature reaches $\sim 175^{\circ} \mathrm{C}$

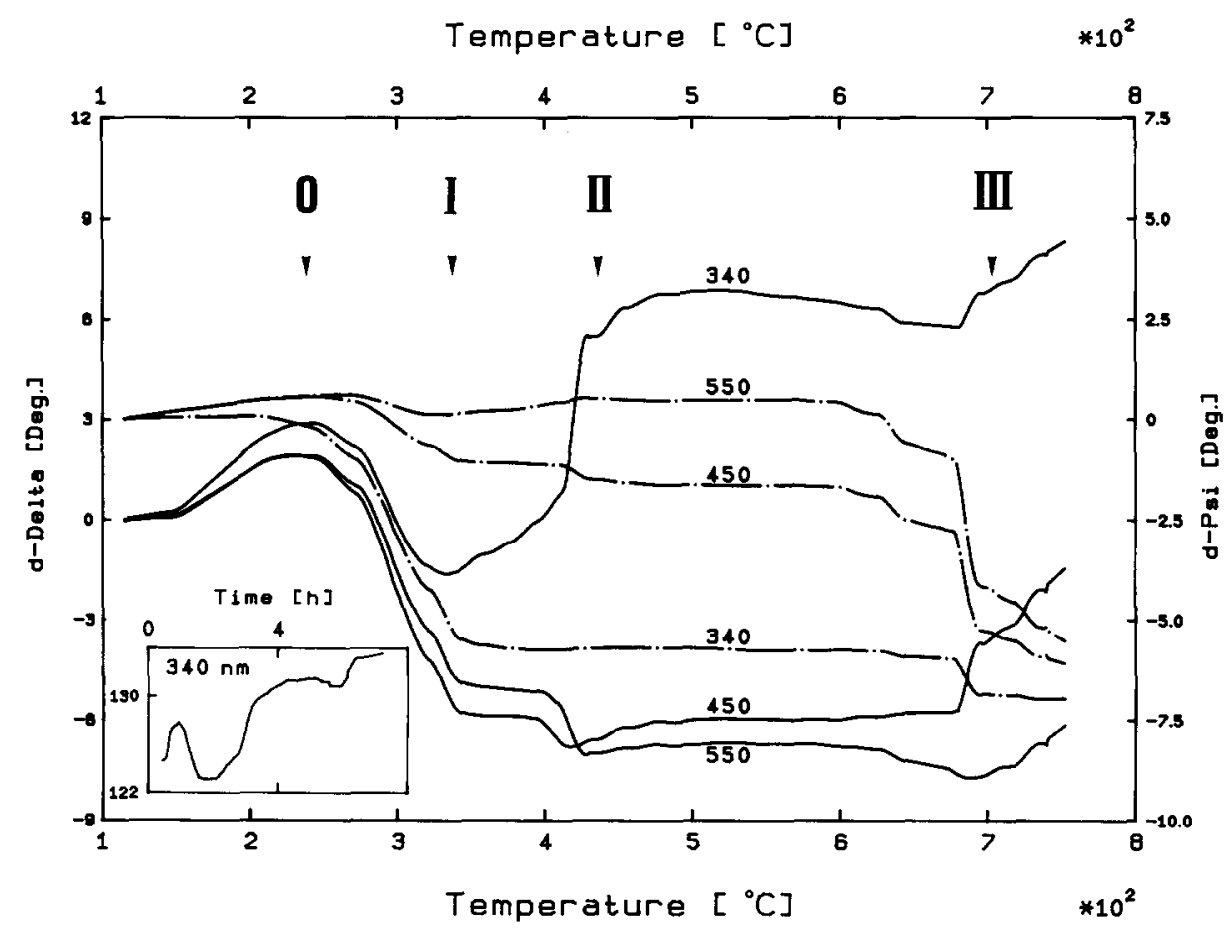

Fig. 3. Changes of $\Delta$ (solid lines) and $\Psi$ (dashed lines) upon heating. The inset shows $\delta \Delta_{340}$ as a function of time. The arrows indicate intermediate states $\mathrm{O}, \mathrm{I}, \mathrm{II}$, and III. 
a very fast process is initiated; the inset shows that the increase is almost instantaneous. This fast increase is generally observed; however, its feature is not always as dominant as in this particular case.

From the experience of the other samples, we believe that there exists a correlation between this initial feature and the $\mathrm{Ti}$ deposition rate; commonly it is observed in thin $(<10 \mathrm{~nm})$ Ti layers that are fastly grown. Further on we shall discuss this feature in more detail.

In the interval $T=250-350^{\circ} \mathrm{C}$, a general decrease of the $\Delta$ and $\Psi$ values is observed. If a simple one-layer model is applied, this should indicate the growth of that layer. At $T \approx 350^{\circ} \mathrm{C}$ this process terminates, and, $\Delta_{340}$ excepted, all signals stabilize. The inset, however, shows that $\Delta_{340}$ was also constant, but started increasing upon a further raise of the temperature. It shows that a metastable intermediate phase has formed.

The slow increase of $\Delta_{340}$ appears to be the prelude to a large one at $T \approx 425^{\circ} \mathrm{C}$, which is accompanied by minor changes of the other values. From the inset it shows that the increase is less fast than suggested by the main figure, i.e., a first glance might indicate a fast phase transition, however, a growth process seems more ap-

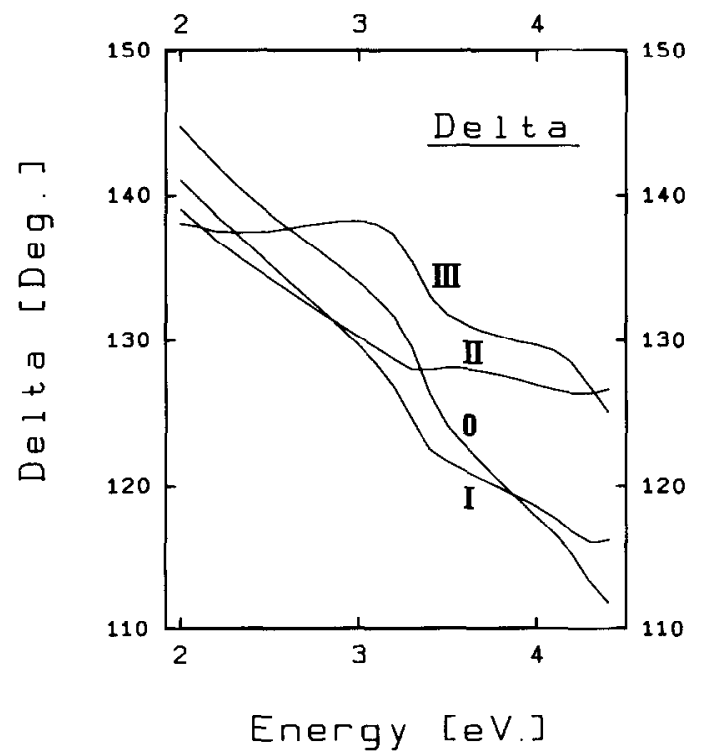

propriate as a possible explanation. Above $T \approx$ $450^{\circ} \mathrm{C}$ a second stable region commences. Finally, at $T \approx 700^{\circ} \mathrm{C}$ a last transition occurs.

From the results presented it appears that we can distinguish four processes, (1) a rapid increase at low temperature followed by (2) a gradual decrease of $\Delta$ and $\Psi$, probably related to a growth process, and yielding a metastable intermediate phase I at $-350^{\circ} \mathrm{C}$, (3) at $T \approx 400^{\circ} \mathrm{C}$, the formation of a meta-stable phase II. At $T \approx 700^{\circ} \mathrm{C}$ wc observe a final transition. The intermediate stages of the kinetics, denoted by states I, II and the final state III, have been characterized by means of spectroscopic ellipsometry. These spectra are displayed in fig. 4 .

\section{Optical analyses}

The optical spectra corresponding with the various metastable intermediate states, are analyzed by means of two different methods. One of the problems which has to be solved, is the determination of the dielectric functions of these intermediate phases. For this reason we have deviated from the simple sequence in which the different phases are observed. First, we shall analyze

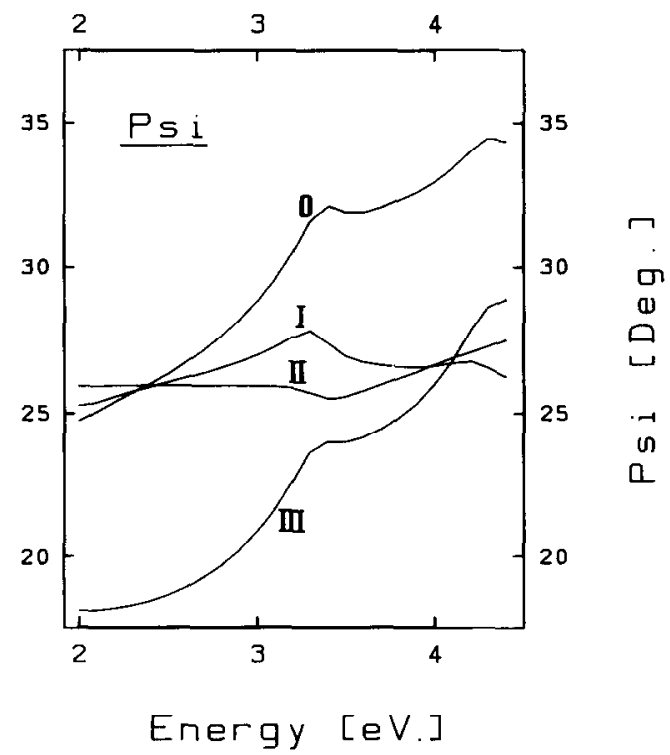

Fig. 4. Ellipsometric spectra of the intermediate states. 
the intermediate state II and then state I. The dielectric functions obtained from these intermediate states are used to investigate the as-deposited Ti layer and the rapid increase of $\Delta$ at $\sim 175^{\circ} \mathrm{C}$, phase $\mathrm{O}$. The investigation of the final state III is reserved to close this section.

\subsection{Intermediate state II}

We shall commence the analyses on the system which will appear the most straightforward, intermediate state II. Its spectrum as depicted in fig. 4 , clearly exhibits a kink and some structure at 3.3 $\mathrm{eV}$. Both can be ascribed to the dielectric function of $\mathrm{c}-\mathrm{Si}$, the kink originating from the onset of the absorbing region of the dielectric function of $\mathrm{c}-\mathrm{Si}$ and the structure from the c-Si peak at $3.3 \mathrm{eV}$ (fig. 1).

Let us assume that we are dealing with a single homogeneous layer on top of a silicon substrate. If so, the pseudo-dielectric function of the top layer can be calculated from the measured optical spectrum and an arbitrary chosen value for the layer thickness. However, a wrongly chosen thickness introduces $\mathrm{c}-\mathrm{Si}$ related features in the dielectric function calculated and therefore, thickness and dielectric function of the top layer can be established from that pseudo-dielectric function that exhibits the least c-Si related characteristics [34].

The result of this analysis is displayed in fig. 5 . The curves have been shifted to improve the presentation; the insets show the non-shifted pseudo-dielectric functions. The pseudo-dielectric function appears to be strongly thickness dependent for $E<3.3 \mathrm{eV}$, which can be explained from the better depth sensitivity for this energy region. For $E>3.3 \mathrm{eV}$, all the curves fall on top of each other, which, as discussed previously, can be attributed to the reduced reflectivity of the silicidesilicon interface; the complex reflection ratio is dominated by the reflection at the vacuum-silicide interface. Our particular interest concerns the pseudo-dielectric function that exhibits the least c-Si related featurcs. This condition is satisficd mostly for $d=27 \mathrm{~nm}$; the curve exhibits the least remnants of the $3.4 \mathrm{eV} \mathrm{c-Si} \mathrm{peak} \mathrm{while} \mathrm{the} \mathrm{global}$ shape of the curves does not show the onset of the absorbing region of $\mathrm{c}-\mathrm{Si}$. From this simple analysis, we may conclude that the layer is quite homogeneous, otherwise the $\mathrm{Si}$ related structure could not be eliminated [34], and is $-27 \mathrm{~nm}$ thick.
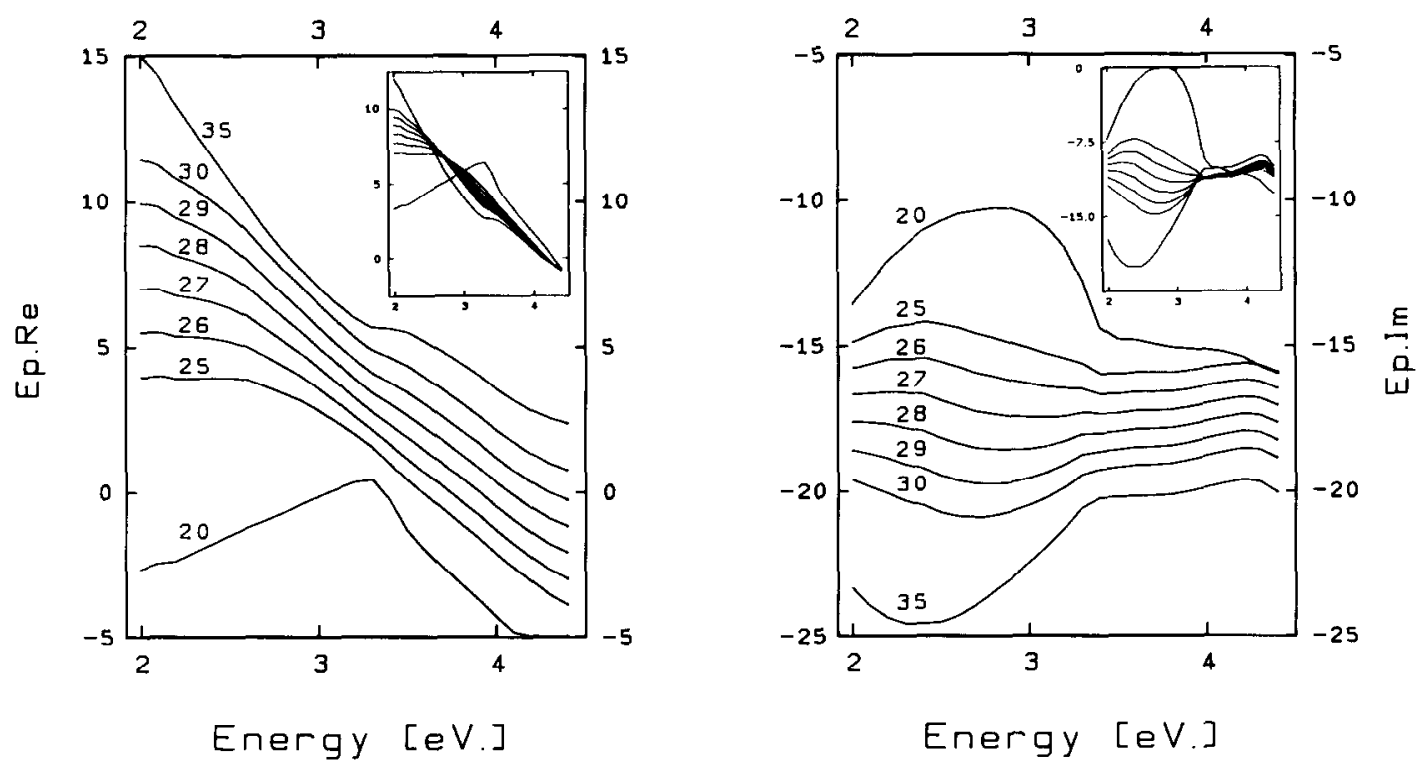

Fig. 5. Pseudodielectric actions of intermediate state II as calculated for several thicknesses. The spectra are shifted to improve the presentation of the c-Si related structure. The insets show the non-shifred spectra. 


\subsection{Intermediate state $I$}

We have applied the same method of analysis onto the spectrum of the intermediate state $I$. Again a homogeneous top layer is assumed. The pseudo-dielectric functions calculated are depicted in fig. 6. The insets show the non-shifted real and imaginary parts. In comparison with fig. 5 the curves do not lie as much on top of each other; the layer is thinner than that of state II. Studying the real part, one sees that it has an S-like shape for $d=18,19$ and $20 \mathrm{~nm}$, which correlates with the dielectric function of c-Si. This shape and the feature at $E=3.4 \mathrm{eV}$ cannot be eliminated at the same time. The same problem appears in the imaginary part of the spectrum. Apparently we do not have a homogeneous layer, nevertheless, the $\mathrm{Si}$ related features are minimized for $d=19 \pm 0.5$ $\mathrm{nm}$, showing that although the layer is inhomogeneous, it has a thickness of approximately $19 \mathrm{~nm}$.

An inhomogeneous layer can be explained by several models. Firstly, one can propose that some surface roughness has been induced. But, state II is homogeneous and therefore we can rule out surface roughness as a possible explanation. Secondly, we have a smooth surface, however, the mixing did not sustain until all the metal was consumed; the mixed layer is covered by a metal Ti layer. This model can be checked; we can easily calculate the dielectric function from the set of $\{\Delta, \Psi\}$ values for a layer sandwiched between the Si substrate and a Ti top layer. For this purpose, we have independently measured the dielectric function of $\mathrm{Ti}, \tilde{\varepsilon}_{\mathrm{Ti}}$ [28]. The total thickness has been fixed at $19 \mathrm{~nm}$ and the thickness of the Ti top layer is chosen as 0.5 and $1 \mathrm{~nm}$. Fig. $7 \mathrm{~b}$ displays the results for the sandwiched mixed layer. The S-like shape of the real part is not really affected whereas the feature at $E=3.4 \mathrm{eV}$ gains in strength. Variation of the total thickness, for example, 18 or $20 \mathrm{~nm}$, did not improve the situation. Hence, a remnant $\mathrm{Ti}$ top layer cannot be considered as an explanation. Thirdly, analogous to a Ti top layer, we can assume a transition layer between the silicon and the intermixed top layer, most probably a layer equal to state II, i.c., the mixing is considered as a continuous diffusion process, a first phase is formed but meanwhile the second-phase growth (state-II-like) has commenced and effectively a two-layer system is obtained. Shown in fig. $7 \mathrm{a}$ are the dielectric functions as calculated for the cases of a state-II-like intermediate layer of thicknesses 0,2 and $4 \mathrm{~nm}$, whereas the total thickness is $19 \mathrm{~nm}$. The shapes
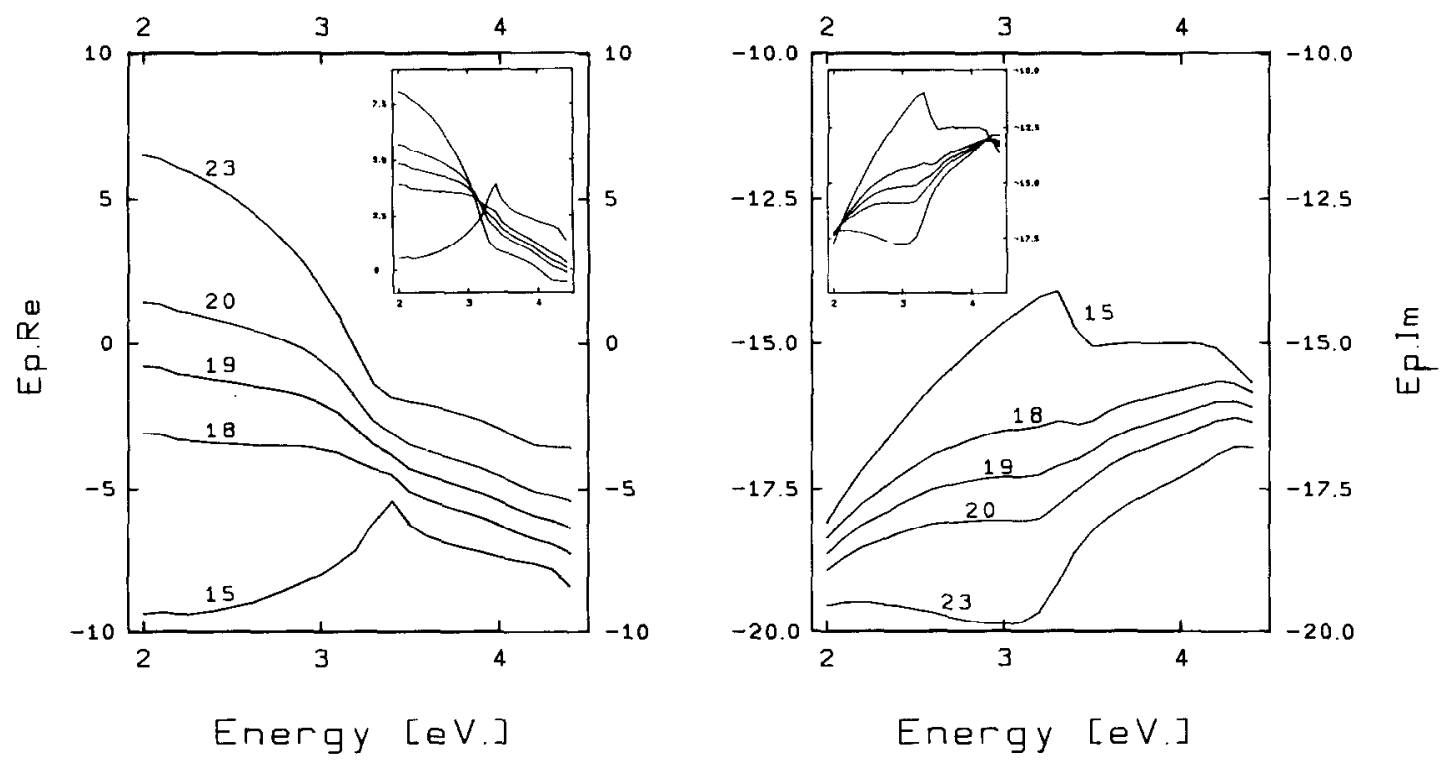

Fig. 6. Shifted and non-shifted (insets) pseudo-dielectric functions of intermediate state $\mathrm{I}$. 

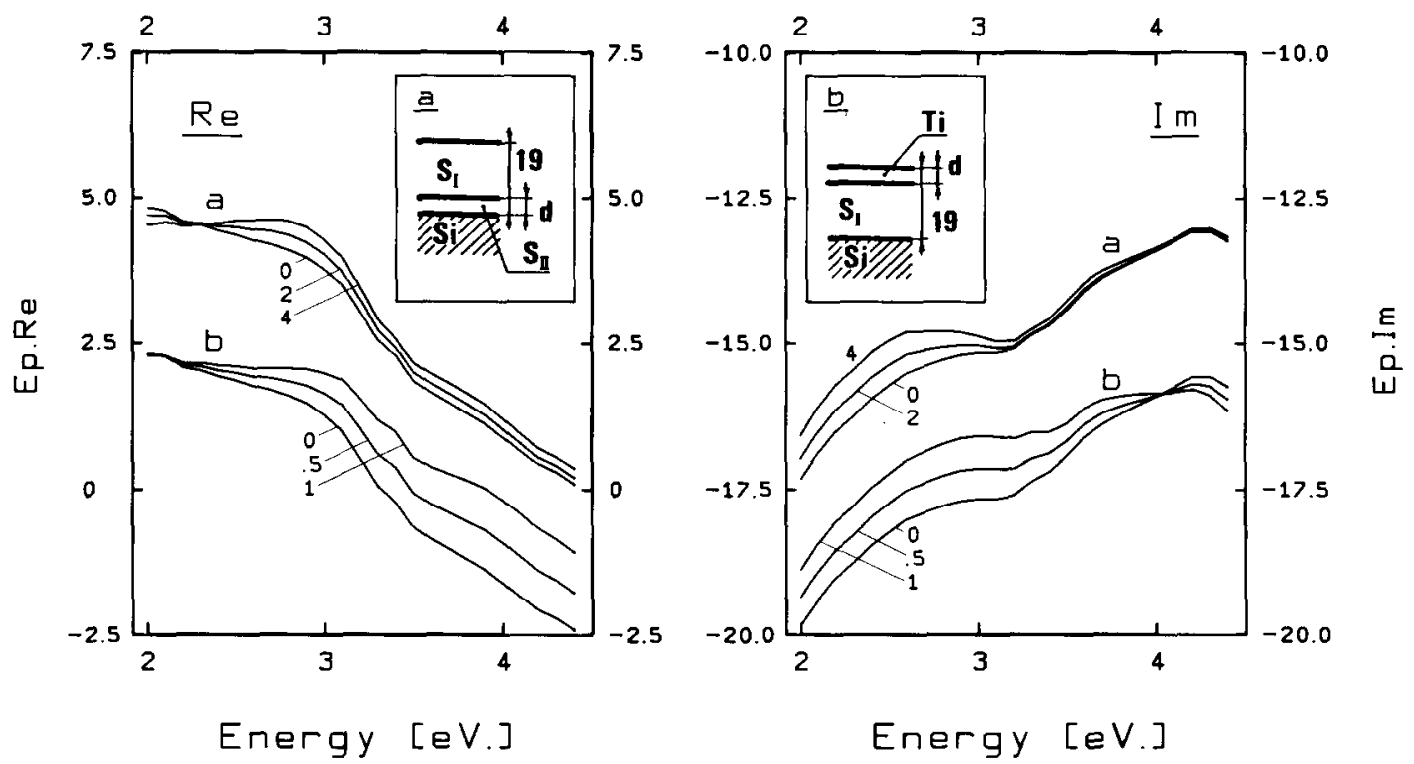

Fig. 7. Pseudo-dielectric reactions of intermediate state I when a state-II-like layer below (a) or a Ti layer above (b) is presumed. The total thickness is constantly $19 \mathrm{~nm}$.

of the different curves do not improve, falsifying this model too.

Thus far we have shown that state I has to be inhomogeneous. A remnant unreacted Ti top layer, nor an already formed, state-II-like intermediate layer do offer a possible explanation. Surface roughness can be ruled out. A suggestion for a possible explanation can be found in the synchrotron-radiation photoemission work of Chambers et al. [16]. They have annealed a $10 \mathrm{~nm}$ Ti overlayer at $340^{\circ} \mathrm{C}$ during $1.5 \mathrm{~h}$, comparable to our sample, and concluded that their layer was effeclively TiSi, but they found an appreciable amount of $\mathrm{Si}$ in a different chemical environment. This second environment is not identified in their work. If there is a second chemical environment for the $\mathrm{Si}$, it may correspond with the inhomogeneity observed presently. A possible explanation then can be that $\mathrm{Si}$ is dissolved in the mixed (TiSi) layer and that this dissolved Si exhibits a large concentration gradient needed for the Si diffusion. Additional support for such large Si concentration gradient, can be found in the work of Raaijmakers [20]. Unfortunately, it is impossible to check whether or not such a model agrees with the optical spectrum.

\subsection{The as-deposited layer and intermediate state $O$}

Thus far we studied the intermediate states I and II. Next, we shall discuss the as-deposited Ti layer and the subsequently formed state $O$. This time we have tackled the problem in another way.
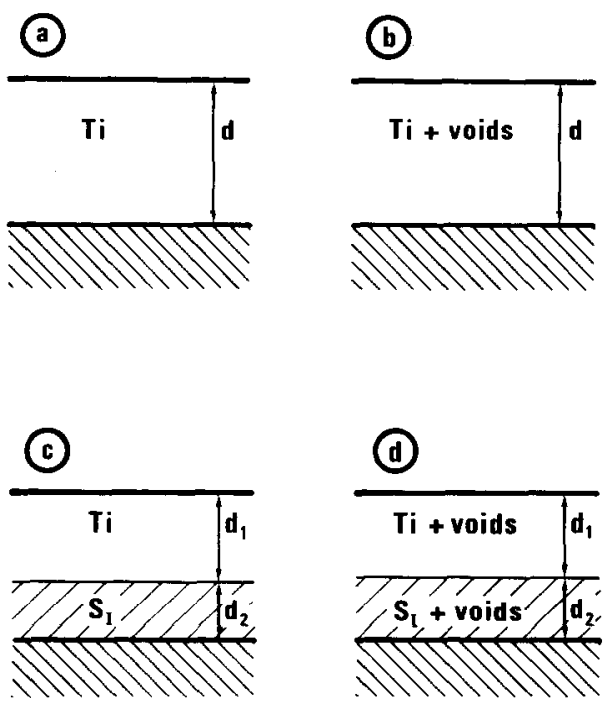

Fig. 8, Optical models $a, b, c$ and $d$ for the as-deposited $\mathrm{Ti}$ layer on $\mathrm{Si}$. 
Table 1

Results of the LRA of the as-deposited Ti layer

\begin{tabular}{|c|c|c|c|c|c|}
\hline \multirow[t]{2}{*}{ Model } & \multicolumn{2}{|c|}{ Mixed layer } & \multicolumn{2}{|c|}{ Titanium layer } & \multirow[t]{2}{*}{ Residue } \\
\hline & $d(\mathrm{~nm})$ & Voids & $d(\mathrm{~nm})$ & Voids & \\
\hline a & - & - & $11.5 \pm 0.4$ & & $3.1 \times 10^{-2}$ \\
\hline b & - & - & $11.0 \pm 0.1$ & $0.11 \pm 0.005$ & $8.5 \times 10^{-3}$ \\
\hline c & $7.5 \pm 0.6$ & - & $6.0 \pm 0.4$ & $4 \quad-$ & $7.0 \times 10^{-3}$ \\
\hline d & $3.9 \pm 0.3$ & $0.28 \pm 0.08$ & $8.4 \pm 0.3$ & $0.04 \pm 0.015$ & $3.5 \times 10^{-3}$ \\
\hline Av. & $3.3 \pm 1.3$ & $0.25 \pm 0.2$ & - & $0.05 \pm 0.10$ & $3.2 \times 10^{-3}$ \\
\hline
\end{tabular}

The models $\mathrm{a}, \mathrm{b}, \mathrm{c}$ and $\mathrm{d}$ correspond with those displayed in fig. 8. The uncertainty limits are listed following the optimized values. The last row presents the average results and their standard deviations of the 14 experiments performed.

We do have the dielectric constant of $\mathrm{Ti}$ at our disposal [28], and if there is an intermixed region formed, which is expected but has to be proven, it shall be state-I-like, and such an interface layer can be modeled by the appropriate dielectric function of that state. Hence, we do have both dielectric functions involved at our disposal, and therefore we can apply linear regression analysis (LRA) [35-37] to compare a number of optional models.

In fig. 8 we introduce the different models. In the first one we have optimized the thickness of a pure $\mathrm{Ti}$ layer on a Si substrate. The result of the fit, $\sigma=3 \times 10^{-2}$ as shown in table 1 is quite poor. A substantial improvement is obtained once the $\mathrm{Ti}$ layer is allowed to contain voids reflecting the $\mathrm{Ti}$ micro-structure $[28,38,39]$ (fig. $8 \mathrm{~b}$ ); the residue becomes $8.5 \times 10^{-3}$, which for the case of this kind of analysis becomes an acceptable fit [35-37]. These voids are incorporated by means of the Bruggeman effective medium thcory [40-43]. However, our main interest concerns the existence of an intermixed layer. The overlayer appears to be $\sim 11 \mathrm{~nm}$ thick, more or less equal to the penetration depth; we should be able to see whether or not there is a state-I-like transition layer beneath the Ti. For this purpose, we have fitted the experimental data to two models, a coarse one, two layers of pure components, the top $\mathrm{Ti}$ and the second layer state-I-like (fig. 8c), and a more advanced one, the two layers with variable thicknesses and void fractions (fig. 8d). In both cases the fits obtained have improved, see table 1. Adding the intermediate layer with varia- ble void fraction has reduced the residue to $3.5 \times$ $10^{-3}$, which is an excellent result and a substantial reduction due to the model improvements. The uncertainty limits for the last model are quite small, the thicknesses obtained are accurate while the void fraction for the $\mathrm{Ti}$ overlayer is very acceptable. The void fraction for the mixed layer is quit large whereas its uncertainty limit is large. This large value of the voids-uncertainty limit is related to the penetration depth; the layer is buried by the $\mathrm{Ti}$ overlayer and its influence on the reflectivity of the sample is less as compared to that of the top layer. However, a large voids-uncertainty limit does not implicate that the void fraction is of no importance, qualitatively, it indicates an intermediate layer that contains a high number of lattice defects or micro-pores as compared to state I. In summary, the results show that the presence of an interface layer can be well established.

The last row, 5, of table 1 lists the average results obtained from 14 experiments performed. The last column presents the average residue, showing that good fits are commonly obtained. The average thickness of the Ti layer is not presented since the layers grown were of variable thickness. The averaged thickness of the mixed layer is $3.3 \mathrm{~nm}$ and although there is a large standard deviation it is small enough to permit the general conclusion that the $\mathrm{Ti}$ and $\mathrm{Si}$ do mix at RT. Another interesting result concerns the average void fraction of the Ti layer and its standard deviation. The latter is about 10 times as large as the average uncertainty limits of the void fraction of the individual fits which shows that the variations among the $\mathrm{Ti}$ void fraction, i.e. its microstructure, has a systematical origin. From the experiments we have obtained the general impression that the void fraction decreases with increasing deposition rate, however, more research is needed to elucidate this dependency properly.

Now that we have the tools to study the low temperature kinetics, we can easily analyse the intermediate state $\mathrm{O}$. We assume that the system has remained a two-layer system, a $\mathrm{Ti}$ top layer above an intermixed interfacial layer similar to the layer of state $I$. Both layers may contain a variable amount of voids, i.e., the fourth model of fig. 8 is applied. Table 2 lists the results thus obtained for 
Table 2

Results of the IRA of the as-deposited Ti layer and after a first, short heating to $T \approx 175^{\circ} \mathrm{C}$

\begin{tabular}{|c|c|c|c|c|c|}
\hline \multirow[t]{2}{*}{ Model } & \multicolumn{2}{|c|}{ Mixed layer } & \multicolumn{2}{|c|}{ Titanium layer } & \multirow[t]{2}{*}{ Residue } \\
\hline & $d(\mathrm{~nm})$ & Voids & $d(\mathrm{~nm})$ & Voids & \\
\hline 1 & $\begin{array}{l}4.9 \pm 0.2 \\
6.3 \pm 0.2\end{array}$ & $\begin{array}{l}0.27 \pm 0.06 \\
0.16 \pm 0.07\end{array}$ & $\begin{array}{l}7.6 \pm 0.2 \\
6.3 \pm 0.2\end{array}$ & $\begin{array}{r}0.09 \pm 0.01 \\
-0.01 \pm 0.02\end{array}$ & $\begin{array}{l}2.5 \times 10^{-3} \\
3.0 \times 10^{-3}\end{array}$ \\
\hline 2 & $\begin{array}{l}3.9 \pm 0.3 \\
6.5 \pm 0.2\end{array}$ & $\begin{array}{l}0.28 \pm 0.08 \\
0.03 \pm 0.06\end{array}$ & $\begin{array}{l}8.4 \pm 0.3 \\
6.0 \pm 0.2\end{array}$ & $\begin{aligned} & 0.04 \\
&-0.02+0.015 \\
&-0.03\end{aligned}$ & $\begin{array}{l}3.5 \times 10^{-3} \\
2.5 \times 10^{-3}\end{array}$ \\
\hline
\end{tabular}

The results are listed for two illustrative samples, the first row presents the LRA prior to the heating, the second row the results after the short anneal.

two representative experiments: the first row presents the analysis for the as-deposited system, the second row that immediately after the short (1-2 $\min$ ) heating.

In both cases we see that the mixed region has grown whereas part of the $\mathrm{Ti}$ layer has been consumed. Further, a striking decrease of the void fraction of both layers is observed, showing that in both layers lattice defects and micro-pores are expelled. Regarding the Ti layer, it shows that we have obtained negative void fractions. This is less

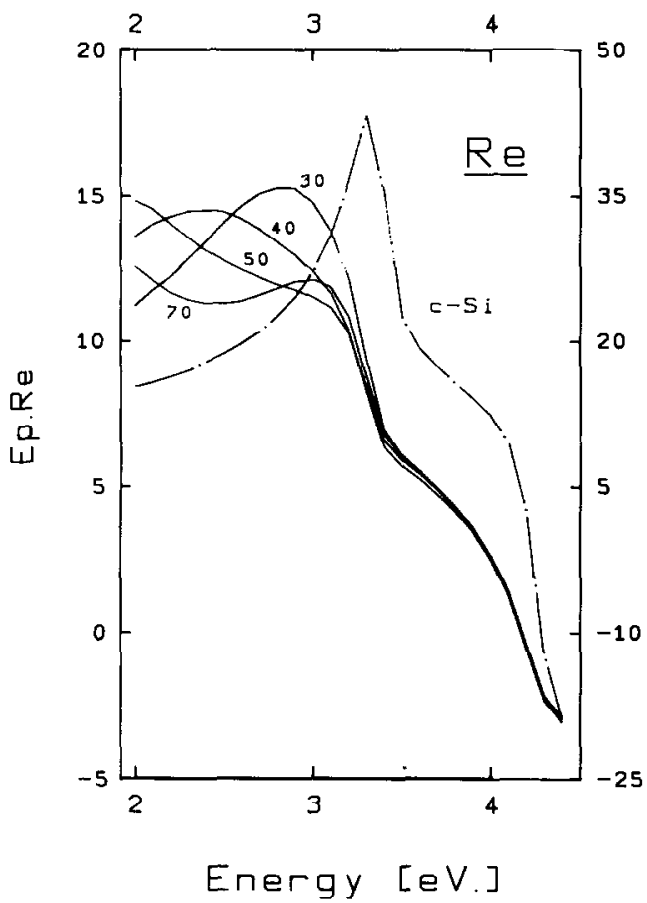

remarkable than it might seem; it shows that the $\mathrm{Ti}$ layer is of better quality as compared to the reference $\mathrm{Ti}$ layer from which we have derived the dielectric function of $\mathrm{Ti}$.

\subsection{Final state III}

At $T \approx 700^{\circ} \mathrm{C}$ the last transition occurs, which, as observed later when the sample was taken out of the UHV system, had caused a substantial roughening of the surface.

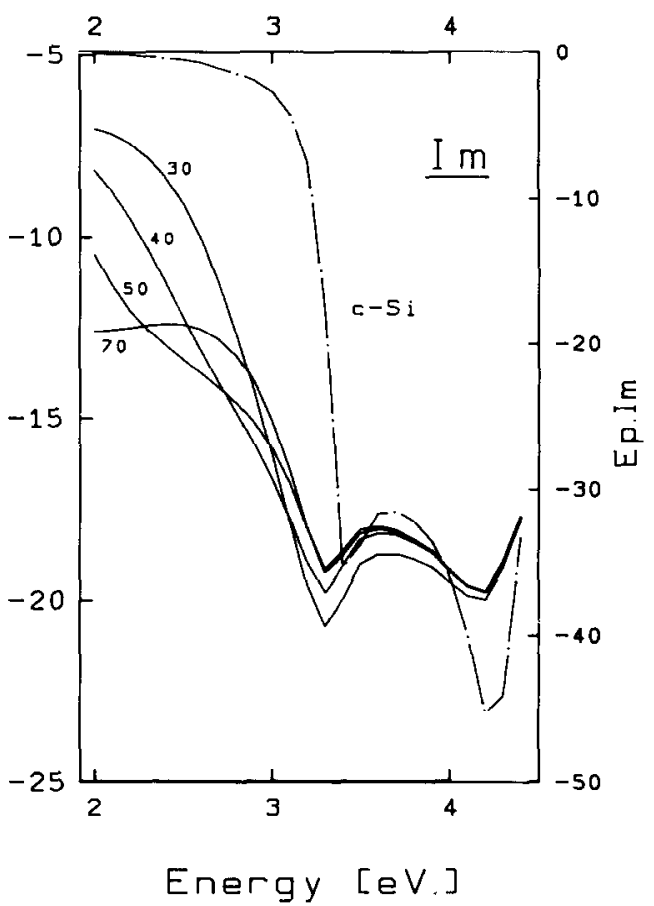

Fig. 9. Pseudo-dielectric function of intermediate state III and the dielectric function of c-Si (dashed-dotted line). The latter is depicted on a different scale. 
Table 3

Analysis of state 4

\begin{tabular}{|c|c|c|c|c|c|}
\hline \multirow[t]{3}{*}{$\mathrm{TiSi}_{2}$} & \multicolumn{3}{|c|}{ Mixed layer } & \multirow{3}{*}{$\begin{array}{l}\text { Top-layer } \\
d \\
(\mathrm{~nm})\end{array}$} & \multirow[t]{3}{*}{ Residue } \\
\hline & \multirow{2}{*}{$\begin{array}{l}d \\
(\mathrm{~nm})\end{array}$} & \multicolumn{2}{|l|}{ Fractions } & & \\
\hline & & $\overline{\mathrm{TiSi}_{2}}$ & $\mathrm{c}-\mathrm{Si}$ & & \\
\hline State 3 & $62 \pm 8$ & $0.70 \pm 0.02$ & $0.21 \pm 002$ & $-0.08 \pm 0.03$ & $1.7 \times 10^{-2}$ \\
\hline Sputtered & $86 \pm 6$ & $0.74 \pm 0.02$ & $0.24 \pm 0.01$ & $-0.27 \pm 0.1$ & $1.0 \times 10^{-2}$ \\
\hline
\end{tabular}

A two-layer model is applied, the top-layer is pure c-Si, whereas the second layer contains c-Si, $\mathrm{TiSi}_{2}$ and voids. Two dielectric functions for $\mathrm{TiSi}_{2}$ are compared, that of state 3 and that of the co-sputtered and annealed $\mathrm{TiSi}_{2}$ layer.

Let us firstly study the pseudo-dielectric constant, as calculated for $d=30,40,50$ and $70 \mathrm{~nm}$. It is depicted in fig. 9. Also shown in the same picture, is the dielectric function of c-Si. Striking is the clear similarity between the pseudo-dielectric function and $\tilde{\varepsilon}_{\mathrm{Si}}$. The c-Si related features are not minimized for any thickness whereas it is not likely that they should disappear for $d<30 \mathrm{~nm}$. Besides, $d=70 \mathrm{~nm}$ has to be several times the information depth and therefore one should not expect the pseudo-dielectric function to be so thickness dependent for energies $<3 \mathrm{eV}$. There is only one conclusion; the top layer does contain c-Si. Further, it shows that the c-Si peak at $3.4 \mathrm{eV}$ has shifted to lower energy, which signifies, as shown previously, a lattice expansion of the silicon. This lattice expansion cannot be attributed to an high sample temperature; the structure near 3.3 $\mathrm{eV}$ has not faded but is clearly visible. There is one explanation only, $\mathrm{Si}$ crystallites have grown within the top layer and stress is introduced within these grains upon cooling down.

Now that we have a faint idea of the layer composition, we can utilize LRA to quantify the layer. The silicon can occur as an overlayer burying the silicide layer beneath, or it may be found as small crystallites within the silicide layer. Another question concerns the silicide; generally a phase transition is observed at $-700^{\circ} \mathrm{C}$ and this should not be omitted since the appearance of the $\mathrm{c}-\mathrm{Si}$ is an indication for a recrystallization of the silicide. Both problems are tackled by a two-layer model. The top layer contains but pure c-Si while the second layer contains three components, $\mathrm{TiSi}_{2}$, c-Si and voids. From the LRA we obtain the optimized layer thicknesses and the composition of the second layer. This model should discriminate between a c-Si overlayer, in which case a significant top layer is found, and a silicide layer containing $\mathrm{c}-\mathrm{Si}$ precipitates. In these analyses we can use either the dielectric constant of state II, or the dielectric function as obtained from the cosputtered $\mathrm{TiSi}_{2}$ sample. (See fig. 11.) Further we have shifted the dielectric function of $\mathrm{c}-\mathrm{Si}$ of the layers in order to meet the lattice expansion. The results of these analyses are summarized in table 3 . Both fits are of a poor quality but still quite exceptable. The fits and the experimental data are plotted in fig. 10, showing that the agreement is

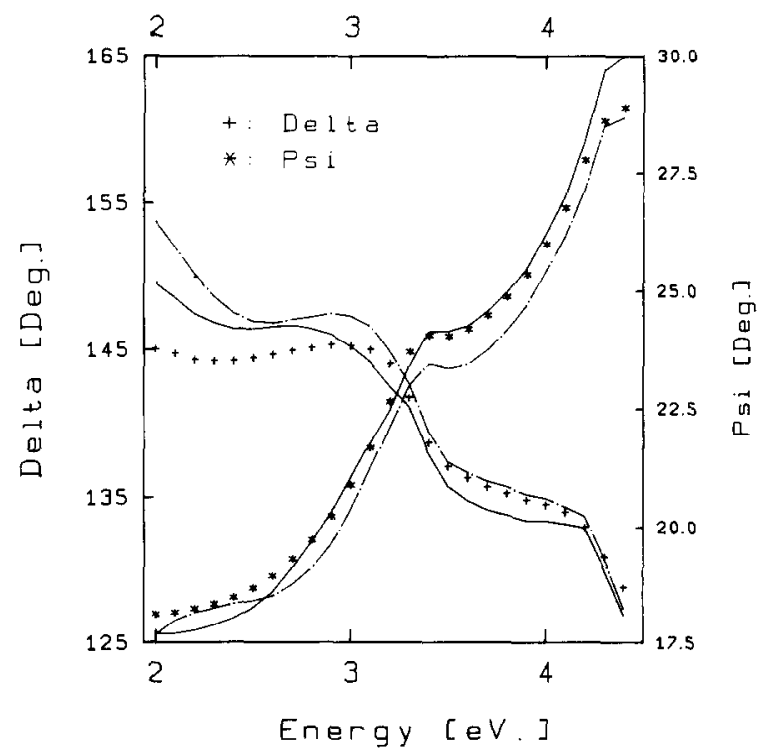

Fig. 10. Best-fits to state III. The dashed lines indicate the fit with the dielectric function of intermediate state II, the solid line that obtained by means of the dielectric function of the co-sputtered $\mathrm{TiSi}_{2}$ layer (see fig. 11). 
not bad. The larger discrepancy for $\Delta$ for $E<3$ $\mathrm{eV}$, as compared to the rest of the fits, is an artifact of the analysis; the LRA minimizes the residue of the Fourier coefficients [39,44], $\Delta$ enters through the term $\cos \Delta$, which is less parameter sensitive for $\Delta$ near $\pi / 2$ as compared to $\Delta$ itself.

The results of the LRA expell the c-Si overlayer in both cases. The fits do favour the dielectric function of the co-sputtered silicide layer which supports the occurrence of a phase transition from a C49 to a C54 structure. The thickness of the layer is physically of no importance; the information depth has been surpassed a number of times and the depth information is hardly present in the spectral ellipsometric data. Therefore, the data are dominated by the surface reflection and one obtains quite accurate information on the composition of the layer. The diminished depth sensitivity and the better compositional sensitivity are reflected by the uncertainty limits obtained.

The above analyses have shown that the silicide layer formed at high temperature is a silicide containing about $25 \%$ of c-Si precipitates. Most probably the silicide is recrystallized into a C54 structure. The thickness of the layer could not be ascertained from the optical data.

\section{Discusssion}

Presently, we will follow the chronological sequence of the reaction kinetics, commencing with the as-deposited Ti layer.

From the analyses of the as-deposited Ti layers, it is shown that the unreacted layer contained an average of $\sim 5 \%$ of voids. Heating the sample to $\sim 175^{\circ} \mathrm{C}$ reduces this void fraction instantaneously. The initially observed high void fraction could be ascribed to surface roughness, however, such an explanation becomes highly unlikely in the scope of the fast annihilation of the voids.

Titanium is a high-melting-point metal, and it is expected to condense into an extremely fine grained, or better, clustered structure [7,11,45-47]. Grain sizes will depend strongly on the growth conditions. in particular the growth rate and substrate temperature. This micro-structure is reflected by the void fraction which is a measure for the number of disordered atoms [38]. Hence, since the as-deposited layer contains a positive void fraction as compared to the reference $\mathrm{Ti}$ layer from which we have obtained the dielectric function of $\mathrm{Ti}$, the as-deposited layer has to be smaller grained than the reference Ti layer. Heating the sample during a short time at a moderate temperature $\left(\sim 175^{\circ} \mathrm{C}\right)$ permits a number of atoms that occupy an energetically less favourable location, to move to a more appropriate site. Because the void fraction reflects the number of disordered atoms, it should be reduced by a reordering process. Such a reduction is presently observed, showing that a number of $\mathrm{Ti}$ atoms that were buried by the subsequently arriving atoms on an energetically unfavourable site, is enabled to reorder.

From the analyses of the ellipsometric spectra of the various as-deposited $\mathrm{Ti}$ layers, it shows unambiguously that an intermixed, state-I-like layer is formed at the $\mathrm{Si}-\mathrm{Ti}$ interface. LRA shows that it contains a high void fraction $(\sim 30 \%)$ which reduces to $-10 \%$ upon the initial heating up to $-175^{\circ} \mathrm{C}$. This reduction of the void fraction indicates an extended reordering of the mixed layer, caused by an enhanced clustering of the atoms. Besides, already at these low temperatures we observe the continued indiffusion of $\mathrm{Si}$ into the metal overlayer and the growth of the intermixed region.

Further heating enhances the Si transport and facilitates the growth of a metastable phase at $\sim 350^{\circ} \mathrm{C}$, referred to as state $\mathrm{I}$. The conversion from the as-deposited layer to state $I$ is accompanied with a volume expansion. The expansion can be calculated from the thickness of the initial Ti layer and that of the finally obtained intermixed layer. We have found that $1 \mathrm{~nm}$ pure Ti eventually yields $2.1 \mathrm{~nm}$ state-I-like material. In the literature it is reported that the formation of $2.7 \mathrm{~nm} \mathrm{TiSi}{ }_{2}$ requires $1 \mathrm{~nm}$ pure Ti, i.e., a volume expansion of 2.7 [1]. Hence, state I shall be most probably Si-enriched TiSi. Such an excess of Si in the layer is supported by the work of Chambers et al. [16], who observed the presence of a certain amount of $\mathrm{Si}$ in a unidentified chemical environment in these layers.

The optical analyses showed that state $I$ is inhomogeneous, however, a remnant $\mathrm{Ti}$ layer nor 
an already formed state-II-like interfacial layer can explain the inhomogeneity. An explanation is offered by an excess of dissolved $\mathrm{Si}$. If there is $\mathbf{S i}$ dissolved in the layer, it should exhibit a concentration gradient causing the Si diffusion until the Ti layer is fully consumed and the formation of a TiSi layer terminated. The concentration gradient then is observed as a severe inhomogeneity. This concept of a large concentration gradient is supported by the work of Raaijmakcrs [8], who reports to have found such a gradient in the case of the intermixing of a stack of sputtered $\mathrm{Ti}$ and amorphous Si layers at $\sim 400^{\circ} \mathrm{C}$.

$\mathrm{Si}$ indiffusion proceeds once the formation of the state-I-like layer has terminated and the temperature is increased. This process sustains until a homogeneous layer, intermediate state II, is formed; the process terminates because all stateI-like material is consumed. The volume expansion occurring in the formation is slightly less than 2.7. Apparently we have obtained a titanium disilicide. However, the temperature of formation is to low to permit the formation of the C54 structured $\mathrm{TiSi}_{2}$ and thus a C49 structure is expected.

In fig. 11 we have depicted the dielectric func-

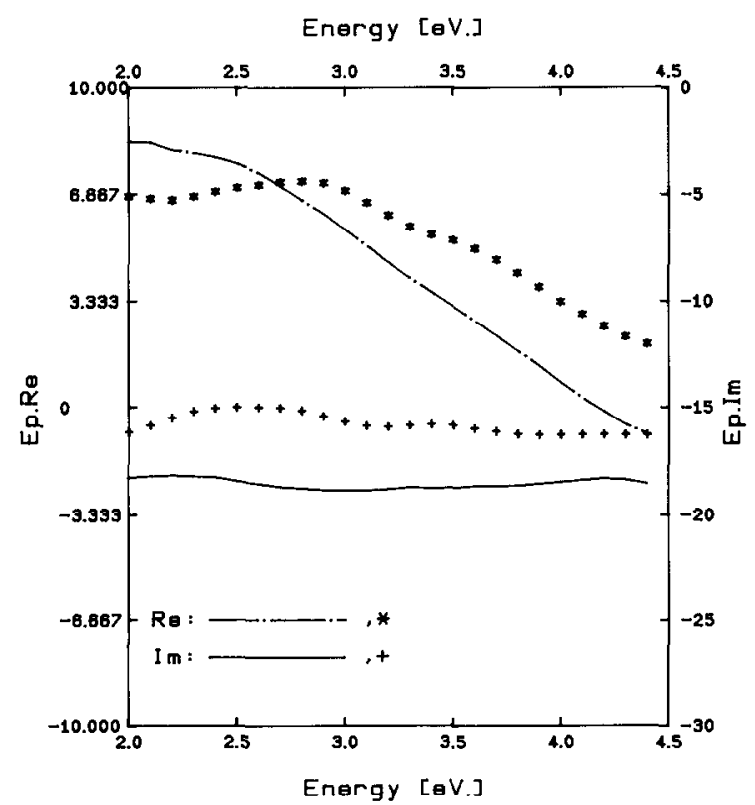

Fig. 11. Best dielectric function of intermediate state II (drawn lines) and that of a co-sputtered and annealed $\mathrm{TiSi}_{2}$ sample. tion state II, $\tilde{\varepsilon}_{I I}$ and the dielectric function independently obtained from a co-sputtered and annealed $\left(T \approx 700^{\circ} \mathrm{C}\right) \mathrm{TiSi}_{2}$ sample. Both functions are, globally, quite similar, however, details differ. The imaginary part of the dielectric constants are nearly flat, indicating that a large number of optical transitions are involved. This observation supports the general idea that d-bands dominate the electronic properties of the silicide.

A final transition is obscrved at $T \approx 700^{\circ} \mathrm{C}$ and a stable layer is obtained. The layer is composed of C54 $\mathrm{TiSi}_{2}$ crystallites and does contain about $25 \%$ of c-Si precipitates. The presence of these c-Si precipitates and the observed surface roughening clearly show that a substantial recrystallization is involved in the transition.

In the following paper we shall present the results of a number of additional investigations. The objective of these measurements is the quantitative characterization of the metastable phases I and II and the final state III by means of RBS, XPS and AES.

\section{References}

[1] S.P. Murarka, Silicides for VLSI Applications (Academic Press, New York, 1981).

[2] P.B. Ghate and C.R. Fuller, in: Semiconductor Silicon 1981, Eds. H. Huff, R. Kriegler and Y. Takeishi (Electrochemical Society, Princetown, NJ, 1981).

[3] V.L. Rideout, Thin Solid Films 48 (1978) 261.

[4] S.M. Sze, Physics of Semiconductor Devices (Wiley, New York, 1981).

[5] J. Derrien, F.A. d'Avitaya, J. Vacuum Sci. Technol. A 5 (1987) 2111

[6] S.P. Murarka, J. Vacuum Sci. Technol. B 4 (1986) 1325.

[7] R. Butz, G.W. Rubloff, T.Y. Tan and P.S. Ho, Phys. Rev. B 30 (1984) 5421.

[8] I.J.M.M. Raaijmakers, Fundamental Aspects of Reactions of Titanium-Silicon Thin Films for Integrated Circuits, PhD Thesis, Eindhoven (1988).

[9] R. Beyers and R. Sinclair, J. Appl. Phys. 57 (1985) 5240.

[10] M.A. Taubenblatt and C.R. Helms, J. Appl. Phys. 53 (1982) 6308

[11] E.J. van Loenen, A.E.M.J. Fischer and J.F. van der Veen, Surface Sci. 135 (1985) 65.

[12] M. Iwami, S. Hashimoto and A. Hiraki, Solid State Commun. 49 (1984) 459.

[13] M. del Giudice, J.J. Joyce, M.W. Ruckman and J.H. Weaver, Phys. Rev. B 35 (1987) 6213. 
[14] A. Franciosi and J.H. Weaver, Physica B 117/118 (1983) 846.

[15] J. Vähäkangas, Y.U. Idzerda, E.D. Williams and R.L. Park, Phys. Rev. B 33 (1986) 8716.

[16] S.A. Chambers, D.M. Hill, F. Ku and J.H. Weaver, Phys. Rev. B 35 (1987) 634.

[17] R.M. Tromp, G.W. Rubloff and E.J. van Loenen, J. Vacuum Sci. Technol. A 4 (1986) 865.

[18] G.W. Rubloff, R.M. Tromp and E.J. van Loenen, Appl. Phys. Letters 48 (1986) 1600.

[19] Y.U. Idzerda, E.D. Williams, R.L. Park and J. Vähäkangas, Surface Sci. 177 (1986) 1028.

[20] I.J.M.M. Raaijmakers, A.H. Reader and H.J.W. van Houten, J. Appl. Phys. 61 (1987) 2527.

[21] W. Bretschneider, G. Beddies and R. Scholz, Thin Solid Films 158 (1988) 255.

[22] E.D. Palik, Handbook of Optical Constants of Solids (Academic Press, New York, 1985).

[23] D.E. Aspnes and A.A. Studna, Phys. Rev. B 27 (1983) 985.

[24] Y.P. Varshni, Physica 34 (1967) 149.

[25] G. Quentel and R. Kern, Surface Sci. 135 (1983) 325.

[26] G.E. Jellinson and F.A. Modine, J. Appl. Phys. 53 (1982) 3745.

[27] P. Winsemius, PhD Thesis, Den Haag (1973).

[28] J.M.M. de Nijs and A. van Silfhout, Thin Solid Films 173 (1989) 1.

[29] D.F. Aspnes and A.A. Studna, I. Appl. Opt. 14 (1975) 220.

[30] A.H.M. Holtslag, $\mathrm{PhD}$ Thesis, University of Twente, Enschede (1986).
[31] J.M.M. de Nijs and A. van Silfhout, J. Opt. Soc. Am. A 5 (1988) 773.

[32] R.M.A. Azzam and N.M. Bashara, J. Opt. Soc. Am. 64 (1974) 639.

[33] J.M.M. de Nijs and A. van Silfhout, J. Opt. Soc. Am. A 5 (1988) 1466.

[34] H. Arwin and D.E. Aspnes, Thin Solid Films 113 (1984) 101.

[35] R.W. Collins, B.G. Yacobi, K.M. Iones and Y.S. Tsun, I. Vacuum Sci. Technol. A 4 (1986) 153.

[36] B.T. Sullivan and R.R. Parsons, Sci. Technol. A 5 (1987) 3399.

[37] J.B. Theeten, D.E. Aspnes, F. Simondet, M. Erman and P.C. Milrau, J. Appl. Phys, 52 (1981) 6788.

[38] D.E. Aspnes, E. Kinsborn and D.D. Bacon, Phys. Rev. B 21 (1980) 3290.

[39] J.M.M. de Nijs, PhD Thesis, University of Twente, Enschede (1989).

[40] C. Grosse and J.-L. Greffe, J. Chem. Phys. 76 (1979) 305.

[41] D.E. Aspnes, Thin Solid Films 89 (1982) 249.

[42] D.E. Aspnes, Am. J. Phys. 50 (1982) 704.

[43] J. Monecke, Phys. Status Solidi (b) 140 (1987) 279.

[44] S.Y. Kim and K. Vedam, Appl. Opt. 25 (1986) 2013.

[45] M. Schneider, A. Rahman and I.K. Schuller, Phys. Rev. 55 (1985) 604.

[46] K.H. Müller, Surface Sci. 184 (1987) 375.

[47] Y. Yamada and K. Yoshida, Appl. Surface Sci. 33/34 (1988) 465. 